Org Lett. 2019 May 17; 21(10): 3568-3571. doi:10.1021/acs.orglett.9b00972.

\title{
Bioactive Rearrangement Products from Aqueous Photolysis of Pharmaceutical Steroids
}

\author{
Nicholas C. Pflug ${ }^{1, \dagger}$, Christopher J. Knutson ${ }^{1}$, Dalma Martinović-Weigelt ${ }^{2}$, Dale C. \\ Swenson ${ }^{1}$, Kristine H. Wammer ${ }^{3}$, David M. Cwiertny ${ }^{4}$, James B. Gloer ${ }^{1,{ }^{*}}$ \\ ${ }^{1}$ Department of Chemistry, University of lowa; lowa City, IA 52242. \\ ${ }^{2}$ Department of Biology, University of St. Thomas; St. Paul, MN 55105. \\ ${ }^{3}$ Department of Chemistry, University of St. Thomas; St. Paul, MN 55105. \\ ${ }^{4}$ Department of Civil \& Environmental Engineering, University of lowa; lowa City, IA 52242.
}

\section{Abstract}

In an ongoing effort to study the environmental fate of endocrine-active steroid hormones, we report the formation of phenolic rearrangement products ( 3 and $\mathbf{4})$ with a novel 6,5,8,5-ring system following aqueous photolysis of dienogest (1) and methyldienolone (2). The structures were established by analysis of 2D NMR and HRMS data, and that of $\mathbf{3}$ was confirmed by X-ray diffraction analysis. These photoproducts exhibit progestogenic and androgenic activity, albeit with less potency than their parent compounds.

\section{Graphical Abstract}
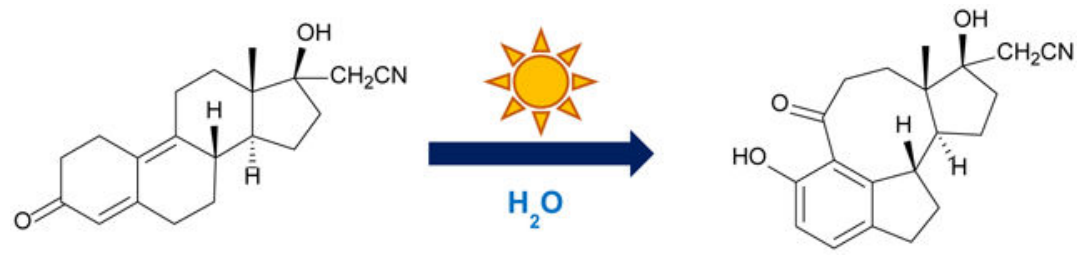

\begin{abstract}
Recent decades of research have been dedicated to evaluating the fate and effects of potent, endocrine-active steroid hormones present in water resources. ${ }^{1-4}$ Once released into the environment, typically via incomplete removal during wastewater treatment, a major fate pathway for many chemicals is photochemical transformation by sunlight. In a previous study, we found that the potent synthetic progestin dienogest (1), which is approved for use as an oral contraceptive (e.g., as a constituent of Natazia ${ }^{\circledR}$ and Qlaira $\left.{ }^{\circledR}\right)$, undergoes rapid
\end{abstract}

\footnotetext{
"Corresponding Author: james-gloer@uiowa.edu.

$\dagger$ Present Addresses: Institute of Biogeochemistry and Pollutant Dynamics, ETH Zurich, 8092 Zurich Switzerland.

Supporting Information

The Supporting Information is available free of charge on the ACS Publications website.

List of reagents, experimental procedures, characterization data, HPLC chromatogram, NMR spectra, UV spectra, and NR dose-

response curves.

The authors declare no competing financial interest.
} 
phototransformation $\left(t_{1 / 2} \sim 1 \mathrm{~min}\right.$ at $\mathrm{pH} 7$ under simulated solar irradiation) to yield numerous transformation products. ${ }^{5}$

Here, we report the isolation and structure elucidation of one of these products, an unusual and unexpected phenolic rearrangement product with a novel 6,5,8,5-ring system for which we propose the name dienogestenol (3). We also explore the generality of this unique rearrangement process through extension to the photolysis of other dienone pharmaceutical steroids [e.g., the androgens methyldienolone (2) and dienedione (5, see below)]. In laboratory experiments, a solar simulator was used to generate photoproduct mixtures expected in sunlit surface waters. All reactions were conducted in aqueous solutions (i.e., $\mathrm{pH}$ buffered with phosphate) to closely simulate natural envronmental conditions. Products 3 and $\mathbf{4}$ were isolated from mixtures by semi-preparative HPLC, and identified by analysis of HRMS and NMR data. The structure of $\mathbf{3}$, including absolute configuration, was confirmed by X-ray diffraction analysis. Finally, agonistic activity of 1-4 was evaluated using in vitro human nuclear receptor assay systems.

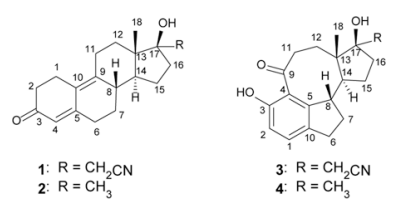

\section{Transformation product identification.}

The scale of these photolysis reactions was limited by low water solubility of the starting materials, but $500 \mathrm{~mL}$ of aqueous solution at an initial concentration of $100 \mu \mathrm{M}$ enabled generation of sufficient amounts of products for characterization. Samples were irradiated for $2 \mathrm{~h}$ (until 1, 2, and $\mathbf{5}$ were below our limit of analytical detection), extracted with chloroform, and the organic phase was collected and concentrated [see Supporting Information for further details regarding reagents, experimental procedures, analytical methods, and quantities of products obtained]. Photolysis of $\mathbf{2}$ showed a product distribution similar to that observed for $\mathbf{1}$ (Figure S1) by HPLC analysis. Products were then isolated via semi-preparative HPLC. Products 3 (from 1) and $\mathbf{4}$ (from 2) are discussed in detail below. Spectroscopic data and assignments for the products are provided in Tables 1 and S1-S3.and in Figures S2-S20. Notably, product $\mathbf{3}$ was also formed from $\mathbf{1}$ when the experiment was conducted at lower concentrations, and at $\mathrm{pH} 2$ or 5 , but a chromatographically interfering product (diene $\mathrm{A}$ in ref. 5) is produced at $\mathrm{pH} 2$ and 5 that does not appear at $\mathrm{pH} 7$, so this scaled-up process was done at $\mathrm{pH} 7$.

\section{Dienogestenol (3). ${ }^{6,7}$}

HREI-TOFMS analysis gave an $\mathrm{M}^{+\bullet}$ ion for 3 at $\mathrm{m} / \mathrm{z} 325.1683$, which established a molecular formula of $\mathrm{C} 20 \mathrm{H} 23 \mathrm{NO} 3$ corresponding to the addition of oxygen and loss of two hydrogen atoms from the starting material 1. A full 2D NMR data set for $\mathbf{3}$ was first collected in $\mathrm{CDCl}_{3}$, leading to proposal of the structure, as well as ${ }^{1} \mathrm{H}$ and ${ }^{13} \mathrm{C} \mathrm{NMR}$ assignments. However, several signals in the aliphatic region overlapped, and given the unusual nature of the proposed structure, a separate set of NMR data was collected in $\mathrm{C}_{6} \mathrm{D}_{6}$ (Table 1; also included in Tables S1 and S2), which afforded better signal resolution, and 
enabled confirmation of the structure assignment. The latter data are employed in the discussion below. The numbering system shown for $\mathbf{3}$ (and $\mathbf{4}$ ) was chosen to facilitate NMR spectral comparison with $\mathbf{1}$ and $\mathbf{2}$, which are numbered according to standard precedent.

${ }^{1} \mathrm{H}$ NMR analysis showed the presence of two ortho-coupled aromatic proton doublets and a sharp, one-proton singlet at $\delta$ 13.3. The downfield shift of the latter suggested an intramolecular hydrogen-bonded phenol group, which was later confirmed by HMBC correlations (see Figure 1 for key correlations and Table $\mathrm{S} 3$ for a complete listing) from the phenolic proton (3-OH) to oxygenated aromatic carbon C-3 at $\delta 163.5$ and protonated upfield aromatic carbon C-2 at $\delta 117.0$ (pink arrows). An additional correlation to nonprotonated aromatic carbon C-4 was observed in the $\mathrm{CDCl}_{3}$ data. These data alone immediately indicated a considerable structural change relative to starting material 1. One of the aromatic proton doublets (H-2) showed correlations to two non-protonated aromatic carbons ( $\mathrm{C}-4$ and $\mathrm{C}-10)$. The other $(\mathrm{H}-1)$ showed correlations to a methylene carbon at $\delta$ 30.4 (C-6; black arrow), to another non-protonated aromatic carbon (C-5) and also to C-3, thereby completing assignment of the aromatic ring (i.e., ring A). COSY data were consistent with assembly of an isolated $\mathrm{CH}_{2} \mathrm{CH}_{2}$ spin-system (C-11-C-12), as well as the extended system corresponding to the linked C-6-C-8 and C-14-C-16 units in structure 3 (Figure 1). Overlap of some of the proton signals for the latter system caused some ambiguities in the analysis which were overcome by complementary interpretation of HSQC and $\mathrm{HMBC}$ data.

$\mathrm{H}_{2}-6$ showed correlations to $\mathrm{C}-7$ and $\mathrm{C}-8$, as well as to aromatic carbons $\mathrm{C}-1, \mathrm{C}-5$, and C-10 (red arrows), while $\mathrm{H}-8$ correlated with C-5 and C-10 (blue arrows), as well as to neighboring carbons $\mathrm{C}-7$ and $\mathrm{C}-14$, thereby enabling assignment of a cyclopentane unit (i.e., ring B) fused to the aromatic ring. $\mathrm{H}_{3}-18$ showed correlations to $\mathrm{C}-12, \mathrm{C}-13, \mathrm{C}-14$, and $\mathrm{C}-17$ (purple arrows) which, together with NMR shift data, indicated that this portion of the structure matched that of the parent compound dienogest $(\mathbf{1}) . \mathrm{H}_{2}-12$ showed correlations to C-13, C-14, and a ketone carbon at $\delta 208.5$ (C-9; green arrows) as well as to C-11 and C-18. $\mathrm{H}_{2}-11$ also showed correlations to the ketone carbon and non-protonated aromatic carbon $\mathrm{C}-4$ (orange arrows), as well as to $\mathrm{C}-12$ and $\mathrm{C}-13$, thereby requiring insertion of the ketone carbon between the isolated $\mathrm{CH}_{2} \mathrm{CH}_{2}$ spin-system $(\mathrm{C}-11-\mathrm{C}-12)$ and the aromatic ring at a position ortho to the phenolic hydroxyl substituent, and rationalizing the downfield shift of the phenolic $\mathrm{OH}$ through intramolecular hydrogen bonding.

H-14 showed correlations to C-5, C-8, C-12, C-13, C-17, C-18 and a methylene carbon at $\delta$ 24.8 (C-15), thereby completing the cyclooctanone unit (i.e., ring C). H2-15 showed correlations to C-8, C-13, C-14, C-17 and a methylene carbon at $\delta 34.1$ (C-16). Finally, the isolated AX pattern signals for $\mathrm{H}_{2}-20$ showed correlations to $\mathrm{C}-16, \mathrm{C}-17$, and the cyano carbon at $\delta 118.1(\mathrm{C}-21)$, thereby completing the tetracyclic structure of $\mathbf{3}$. The relative configuration of $\mathbf{3}$ was assigned on the basis of key NOESY correlations from $\mathrm{H}-8$ to $\mathrm{H}_{3}-18$ and from $\mathrm{H}-14$ to $\mathrm{H}_{2}-20$ (Figure 1), indicating that the overall configuration is unchanged from those of the corresponding stereocenters of the parent compound 1. Single-crystal Xray diffraction analysis using $\mathrm{Cu} \mathrm{Ka}$ radiation confirmed the proposed structure of photoproduct 3 and a perspective ORTEP plot is shown in Figure 2. The value of the Flack parameter, 0.01(7), allowed assignment of the $8 S, 13 S, 14 S, 17 R$ absolute configuration, 
verifying that no stereochemical change had occurred in the D-ring of the molecule.

Surprisingly, to our knowledge, no compound having the tetracyclic core structure shown in 3 has been previously reported in the literature as either a synthetic or natural product. The tricyclic unit comprised of rings A-C has previously been described as a subunit of synthetic analogues of dibenzocyclooctenes, which are known to stimulate the central nervous system and display various biological activities, including anal-gesic, sedative, antihypertensive, vasodilatory, and antihistaminic effects. 8,9

\section{Methyldienolol (4). 7,10}

Because of the unexpected features of product $\mathbf{3}$, efforts were undertaken to explore whether structurally similar steroidal dienones would afford the same kind of rearrangement products. Thus, a sample of commercially available analogue $\mathbf{2}$ (methyldienolone) was subjected to the same conditions, indeed affording an analogous product that was identified by independent 2D NMR analysis. HR-ESITOFMS data established a molecular formula of $\mathrm{C}_{19} \mathrm{H}_{24} \mathrm{O}_{3}(\mathrm{M}-\mathrm{H})^{-} \mathrm{m} / \mathrm{z} 299.1654$, again corresponding to the addition of one oxygen and loss of two hydrogen atoms relative to the starting material 2. The ${ }^{1} \mathrm{H}$ and ${ }^{13} \mathrm{C}$ NMR data (Tables S1 and S2) were nearly identical to those of $\mathbf{3}$, showing only very minor shift differences, aside from the replacement of the $\mathrm{CH}_{2} \mathrm{CN} \mathrm{AX}$ pattern with a methyl singlet, as expected for a product arising from 2. The HMBC (Table S3) and COSY data were analogous to those observed for $\mathbf{3}$. The relative configuration of $\mathbf{4}$ was again assigned on the basis of NOESY correlations observed from $\mathrm{H}-8$ to $\mathrm{H} 3-18$ and from $\mathrm{H}-14$ to $\mathrm{H}_{3}-20$, indicating that the configuration at all retained stereocenters is similarly unchanged from that of the parent compound 2 .

Interestingly, we failed to see evidence of an analogous rearrangement product upon photolysis (to levels below our limit of analytical detection) of $\mathbf{5}$, another similar dienone analogue. It is possible that its 17-keto group interferes in some way, or perhaps redirects the products along a different pathway. It is also possible that a similar product does form, but not in sufficient quantity for detection under the conditions employed. A literature search revealed that, like dienedione, many commercially available dienone analogues incorporate a non-conjugated ketone functionality. If the different results observed for dienedione are indeed due to the presence of such a ketone moiety, these other dienone species may be similarly unlikely to undergo an analogous rearrangement upon photolysis. There are a few other dienones that lack such functionality and might therefore be additional candidates likely to undergo such a process (e.g., dienolone; 6), although further compounds were not explicitly tested in this work.

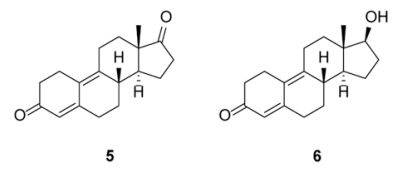

It was not straightforward to discern the mechanistic pathway by which this rearrangement process takes place. Aside from aromatization, a major feature of the rearrangement products is a tetrasubstituted A-ring, given that the parent steroids have only three substituents on the A-ring. In addition, the substitution pattern in the A-ring in relation to the 
oxygen atom substituent is different in products and parents. Although methylene C-6 is 1,3positioned relative to the oxygen substituent in the parent structures, it is 1,4-positioned in the products. Presumably, the process proceeds via a radical mechanism. An initial step could involve formation of an enedione intermediate via photochemical reaction of an excited triplet $\pi / \pi^{*} 9,10$-di-radical intermediate with ground state triplet oxygen, leading to an oxidative $\pi$-bond cleavage akin to oxidative indole ring-opening observed during the aqueous photolysis of tryptophan, and analogous to that known for other systems. ${ }^{11-14}$ Such a fission of the B-ring would open the door to substantial reorganization of the ring system, but arrival at the final skeleton would still require significant rearrangement that is enigmatic without a detailed mechanistic study.

\section{Biological activity assessment.}

Samples of $\mathbf{1}$ (positive control) and $\mathbf{3}$ (tested at 50 and $100 \mu \mathrm{M}$ in triplicate) were first screened against 48 human nuclear receptors (hNR) using a commercially available cellular biosensor system (TRANS-FACTORIAL ${ }^{\mathrm{TM}}$ assays Attagene Inc. Morrisville, $\mathrm{NC}^{15-16}$ ). Product 3 retained progesterone receptor (PR) and estrogen receptor (ER $a$ and $\beta$ ) agonistic activity, but was less potent than 1 (Figure 3). Costs limited evaluation of other analogues with this approach. Instead, further analyses of all analogues (1-4) were conducted with androgen receptor (AR), PR, and ERa reporter assays (Indigo Biosciences, State College, PA). ${ }^{17}$

As shown in Table 2, analysis of $\mathbf{3}$ revealed that it retained substantial PR and AR activity (expressed as EC50 values, see SI Figures S21-S24 for dose response curves), with 280fold reduction in PR and $\sim 50$-fold reduction in AR activation compared to that of parent 1 . Likewise, analysis of $\mathbf{4}$ revealed similarly retained PR and AR activity, with 100-fold reduction in $\mathrm{PR}$ and $\sim 20$-fold reduction in AR activation compared to that of parent 2 . Both photoproducts showed activation of ERa, but only at high concentrations (i.e., $25 \mu \mathrm{M}$; see Figure S24).

Although photoproducts $\mathbf{3}$ and $\mathbf{4}$ exhibited decreased PR and AR activation relative to their respective parent compounds $\mathbf{1}$ and $\mathbf{2}$, they nonetheless retain low- $\mu \mathrm{M}$ to sub-nM activity. This was somewhat unexpected given the considerable change in core tetracyclic structure. In addition, 4 exhibited noteworthy AR activation, with an $\mathrm{EC}_{50}$ of $\sim 0.2 \mathrm{nM}$. This is of similar potency to that measured for the positive AR control (i.e., 6a-fluoro-testosterone; EC50 $~ 0.1 \mathrm{nM}$ ), which is $\sim 2$ - to 4-fold more potent than the endogenous AR ligand testosterone. ${ }^{18-19}$

The retained bioactivities of $\mathbf{3}$ and $\mathbf{4}$ and other photoproducts of $\mathbf{1}^{5}$ have implications for the environmental fate of potent bioactive steroids and associated exposure risks to ecosystems and humans, as they raise concerns about current risk-assessment paradigms. Similar results may be likely for other dienone steroids. Moreover, these findings show that even substantial structural rearrangements induced by environmental transformation of such compounds may not be sufficient to eliminate their endocrine-disrupting potential.

Org Lett. Author manuscript; available in PMC 2020 March 06. 


\section{Supplementary Material}

Refer to Web version on PubMed Central for supplementary material.

\section{ACKNOWLEDGMENTS}

Support for this work from NSF (CHE-1609791, CBET-1335711, and CBET-1336165), and the University of Iowa (UI; research fellowship to NCP) is gratefully acknowledged. Support for the $600 \mathrm{MHz}$ NMR and HRMS instruments was provided by grants from NIH (S10 RR025500) and NSF (CHE-0946779), respectively. We thank Dr. Lynn Teesch and Mr. Vic Parcell of the UI HRMS Facility for support in product analysis.

\section{REFERENCES}

(1). Segner H; Casanova-Nakayama A; Kase R; Tyler CR, Gen. Comp. Endocrinol 2013, 191, 190_ 201. [PubMed: 23763869]

(2). Bertram MG; Saaristo M; Baumgartner JB; Johnstone CP; Allinson M; Allinson G; Wong BBM, Horm. Behav 2015, 70, 85-91. [PubMed: 25797925]

(3). Orlando EF; Ellestad LE, Gen. Comp. Endocrinol 2014, 203, 241-249. [PubMed: 24759355]

(4). Cwiertny DM; Snyder SA; Schlenk D; Kolodziej EP, Environ. Sci. Technol 2014, 48, $11737-$ 11745. [PubMed: 25216024]

(5). Pflug NC; Hankard MK; Berg SM; O’Connor M; Gloer JB; Kolodziej EP; Cwiertny DM; Wammer KH, Environ. Sci.: Processes Impacts 2017, 19, 1414-1426.

(6). Dienogestenol (3): colorless crystals from MeOH; mp 183-185 ${ }^{\circ} \mathrm{C}$; [a]20d -63 (c0.0006, $\mathrm{CH} 2 \mathrm{Cl} 2$ ); HREITOFMS m/z 325.1683 [M]+ (calcd for C20H23NO3, 325.1678); UV (MeOH) $\lambda \max 222$ (log e 4.47), 266 (4.31), 354 (3.88); 1H, 13C, and HMBC NMR data see Table 1 and Tables S1-S3.

(7). Pflug N.C., Ph.D. Dissertation, University of Iowa, 2017.

(8). Frey A; Galantay E, Dibenzocyclooctenes. US patent 33822421968.

(9). Galantay E, Aminohydroxyhexahydro-cyclopentadiben-zocyclooctenes. US patent 34911501970.

(10). Methyldienolol (4): colorless glass; [a]20d -44 (c0.00067, CH2Cl2); HRESITOFMS m/z 299.1654 [M - H]- (calcd for C19H23O3, 299.1647); UV (MeOH) $\lambda \max 218$ (log e 4.44), 266 (4.19), 354 (3.77); 1H, 13C, and HMBC NMR data, see Tables S1-S3.

(11). Baltrusaitis J; Patterson EV; O’Connor M; Qu S; Kolodziej EP; Cwiertny DM, Environ. Sci. Technol 2016, 50, 6753-6761. [PubMed: 26800354]

(12). Borden WT; Hoffmann R; Stuyver T; Chen B, J. Am. Chem. Soc 2017, 139, 9010-9018. [PubMed: 28613073]

(13). Nakagawa M; Watanabe H; Kodato S; Okajima H; Hino T; Flippen JL; Witkop B, Proc. Natl. Acad. Sci 1977, 74, 4730-4733. [PubMed: 16592461]

(14). Pattison DI; Rahmanto AS; Davies MJ, Photochem. Photobiol. Sci 2012, 11, 38-53. [PubMed: 21858349]

(15). Martin MT; Dix DJ; Judson RS; Kavlock RJ; Reif DM; Richard AM; Rotroff DM; Romanov S; Medvedev A; Poltoratskaya N; Gambarian M, Chem. Res. Toxicol 2010, 23, 578-590. [PubMed: 20143881]

(16). Romanov S; Medvedev A; Gambarian M; Poltoratskaya N; Moeser M; Medvedeva L; Diatchenko L; Makarov S, Nat. Methods 2008, 5, 253-260. [PubMed: 18297081]

(17). Indigo Biosciences Human Androgen Receptor (NR3C4, AR) Reporter Assay System. Technical Manual version 7.1, 1-12.

(18). Choe YS; Katzenellenbogen JA, Steroids 1995, 60, 414-422. [PubMed: 7570716]

(19). Kincl FA; Dorfman RI, Steroids 1964, 3, 109-122. 

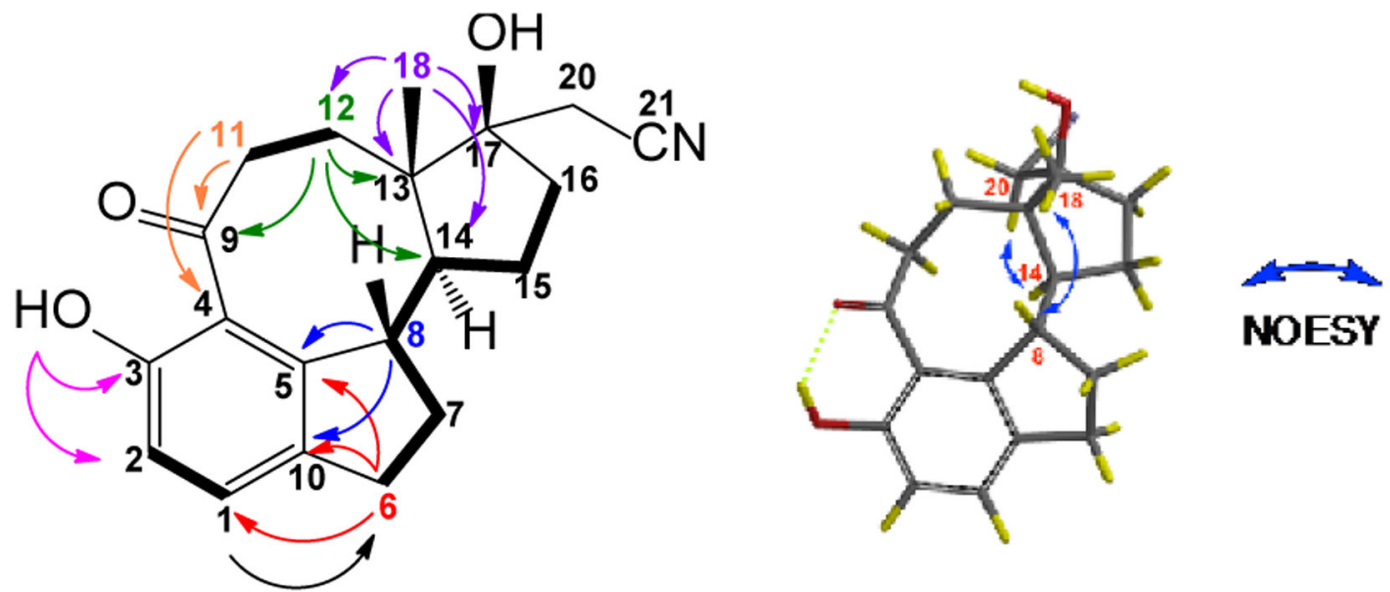

Figure 1.

Key HMBC, COSY (left), and NOESY (right) correlations observed for photoproduct 3 . The structure on the right is an energy-minimized model. 


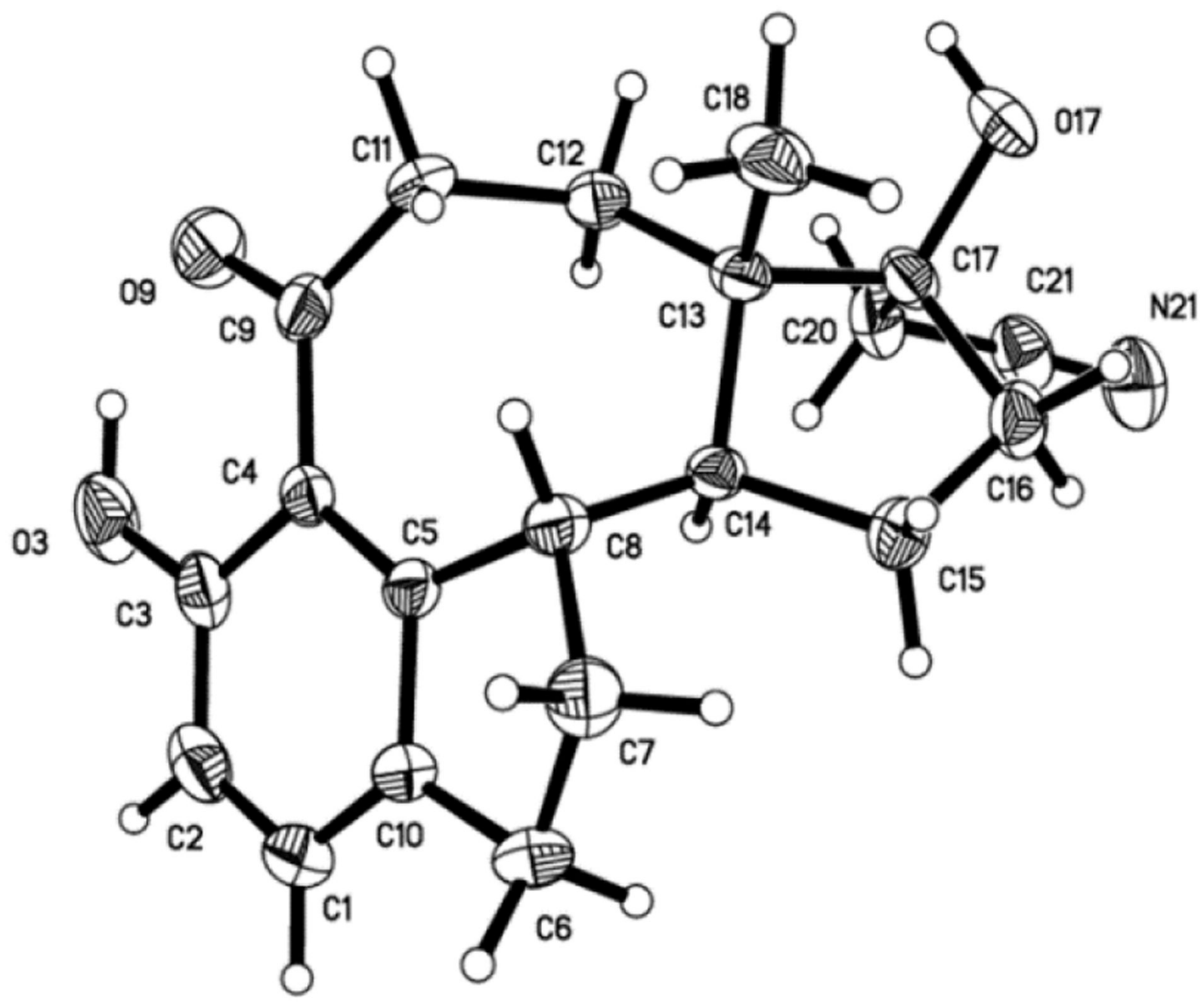

Figure 2.

Thermal ellipsoid representation of photoproduct 3 . 

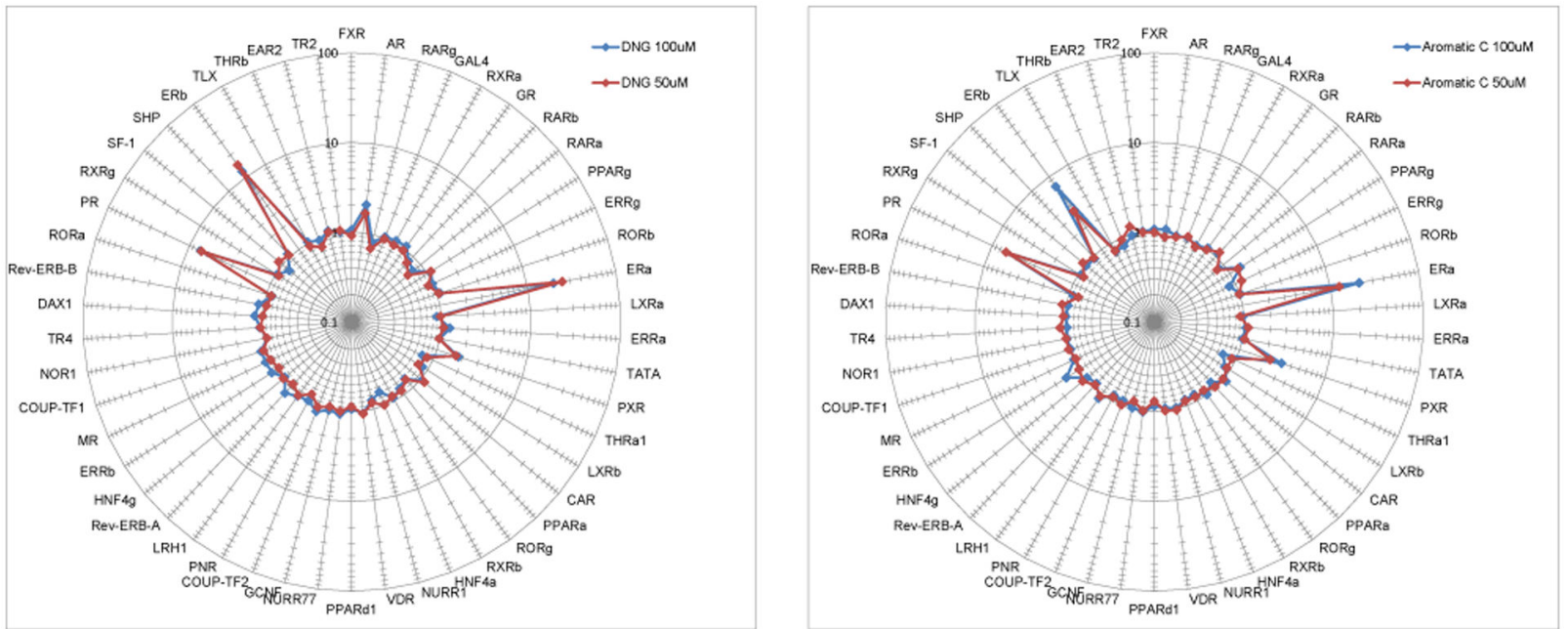

Figure 3.

Effect of $\mathbf{1}$ (left) and $\mathbf{3}$ (right) on the activity of 48 human nuclear receptors in HepG2 cells. Activities were determined as fold-induction values versus vehicle-treated control cells. Graph shows mean fold-induction data plotted in logarithmic scale. 
Table 1.

\begin{tabular}{|c|c|c|c|}
\hline \multirow{2}{*}{ 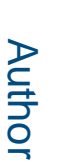 } & \multicolumn{3}{|c|}{${ }^{1} \mathrm{H}$ and ${ }^{13} \mathrm{C}$ NMR Spectroscopic Data for 3} \\
\hline & position & $\delta_{\mathrm{c}}^{a}$ & $\delta_{\mathrm{h}}$ mult. $(J \text { in } \mathrm{Hz})^{b}$ \\
\hline \multirow{5}{*}{ 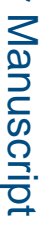 } & 1 & 131.7 & $6.97 \mathrm{~d}(8.3)$ \\
\hline & 2 & 117.0 & $6.99 \mathrm{~d}(8.3)$ \\
\hline & 3 & 163.5 & \\
\hline & 4 & 116.4 & \\
\hline & 5 & 150.5 & \\
\hline \multirow{15}{*}{ 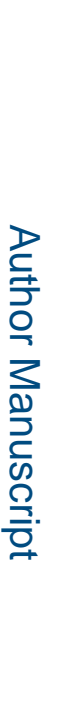 } & 6 & 30.4 & $2.37 \mathrm{~m}, 2.46 \mathrm{ddd}(16,8.8,7.5)$ \\
\hline & 7 & 31.1 & $1.60 \mathrm{ddd}(11,7.5,3.9), 1.72 \mathrm{~m}$ \\
\hline & 8 & 43.4 & $3.11 \mathrm{td}(7.4,3.9)$ \\
\hline & 9 & 208.5 & \\
\hline & 10 & 134.2 & \\
\hline & 11 & 36.3 & $2.30 \operatorname{td}(14,1.5), 2.64 \mathrm{dd}(14,8.5)$ \\
\hline & 12 & 29.4 & $0.81 \mathrm{br} d d(14,8.5), 1.46 \mathrm{br} \mathrm{t}(14)$ \\
\hline & 13 & 47.9 & \\
\hline & 14 & 48.1 & $1.08 \mathrm{~m}$ \\
\hline & 15 & 24.8 & $1.07 \mathrm{~m}, 1.21 \mathrm{~m}$ \\
\hline & 16 & 34.1 & $1.43 \mathrm{~m}, 1.72 \mathrm{~m}$ \\
\hline & 17 & 81.2 & \\
\hline & 18 & 13.9 & $0.63 \mathrm{~s}$ \\
\hline & 20 & 27.4 & $1.13 \mathrm{~d}(16), 1.68 \mathrm{dd}\left(16,1.5^{c}\right)$ \\
\hline & $3-\mathrm{OH}$ & 118.1 & $13.33 \mathrm{~s}$ \\
\hline
\end{tabular}

${ }^{a} 150 \mathrm{MHz}$

${ }^{b} 600 \mathrm{MHz}$. HSQC and HMBC data were used to make ${ }^{13} \mathrm{C}$ NMR shift assignments.

${ }^{c}$ Long-range coupling to an adjacent $\mathrm{CH}_{2}$ proton. A similar $1.2-\mathrm{Hz} J$-value appears in the spectrum of the starting material. 
Table 2.

PR, AR, and ERa agonist activity expressed as EC50 values for 1-4 and positive controls.

\begin{tabular}{llll}
\hline compound & PR EC $_{\mathbf{5 0}}(\mathbf{n M})$ & $\mathbf{A R ~ E C}_{\mathbf{5 0}}(\mathbf{n M})$ & $\mathbf{E R ~ E C}_{\mathbf{5 0}}(\mathbf{n M})$ \\
dienogest (1) & 3.6 & 0.3 & $>25000$ \\
methyldienolone (2) & 0.8 & 0.01 & 4231 \\
dienogestenol (3) & 1010 & 16.2 & $>25000$ \\
methyldienolol (4) & 82.9 & 0.2 & $>25000$ \\
progesterone * & 3.6 & - & - \\
6<x-fluoro-testosterone ** & - & 0.1 & - \\
17B-estradiol *** & - & - & 0.4 \\
\hline * & & & \\
positive PR control; & & & \\
** & &
\end{tabular}

Org Lett. Author manuscript; available in PMC 2020 March 06. 